Another objection is that boats of British nationality are not the only ones engaged in the small fish trade, and it is true that during the summer months a number of German, Dutch, and Danish boats are occupied in catching small plaice. But they are all of small tonnage, some of them only open boats ; and I understand that from the manner in which the trawl is handled by German and Danish boats no injury is done to the unmarketable fish, whilst the saleable part of the catch appears to be exported chiefly to London. Hence the proposed measures of prohibition would give no advantage to these nations. The German steam trawlers, according to my information, do not molest the small plaice at all. Of the proceedings of the Dutch bombs I have little knowledge, but from the small size of their gear, their share in the destruction cannot be a very large one. Foreign-caught fish, except Norwegian salmon and mackerel and Dutch soles, including only a small percentage of undersized fish, rarely come to the Grimsby market, but on two occasions large consignments of small plaice, comprising, as I compute, some $3 \mathrm{I}, 000 \mathrm{fish}$, were sent from Denmark, and recently a consignment of turbot has arrived from Norway. These last fish were about 300 in number, all undersized, viz. from $9 \frac{1}{2}$ to 17 inches, whilst 4 were only from 8 to 9 inches. This is the only instance which has come under my notice of any considerable number of turbot less than 12 inches being present in the market, and, as we have seen, our own fishermen were not concerned in it.

The last and perhaps the most important objection arises from the difficulty in allowing for that variation in the size of fish of the same species on different parts of our own coast to which Mr. Calderwood alluded in the last number of the Journal, p. 208. The impossibility of utilizing a uniform size limit for all districts sufficiently exemplified by the limit of II inches for the plaice proposed by the Conference of last February, which was the result of a compromise between the trade representatives of the North Sea and south and west coast districts. While perhaps unnecessarily high for the Plymouth district, we have seen that it is altogether too small for the North Sea. The difficulty of having different limits, of local application, will only be felt at such a central port or market as London, to which fish are brought, whether by rail or sea, from all districts, but with proper organization the obstacle does not seem insuperable. It is conceivable that the law might be evaded by running cutters from boats fishing in one district to the parts of another, where the limit was lower, but it is little likely that the firms which are in a position to undertake them, would lend themselves to such operations. There is not the slightest reason to apprehend a general conspiracy of evasion amongst the fishermen, and the boats which respected the law would form a more efficient police than all the cruisers in the navy, so far as one may judge by the conditions on the Scotch coast, where convictions of trawlers for infringement of the territorial restriction are frequently secured by the evidence of local line fishermen.

I must leave to others, who are acquainted with the local conditions, to decide whether the imposition of a size limit is desirable in other districts, but for the North Sea I have not the slightest hesitation in recommending this method of legislation, in the terms I have proposed above, as cheaper and likely to be infinitely more efficacious than any other that can be devised in maintaining the supply of the more important kinds of flat-fish. I need hardly observe that its application to the halibut, which is chiefly a line fish, could not fail to be beneficial to that species, since there is no question but that fish caught on the hook will usually survive if returned ; ${ }^{\mathrm{T}}$ but I do not think that the limit need be as high as the biological one, owing to the difference in the conditions of the trawl and line fisheries.

I am not prepared to enter at present into the question of mesh legislation, beyond pointing out that it appears to be the only methud by which the destruction of immature round fish, notably haddock and whiting, can be checked, since these species are fatally injured by being caught in the trawl, and would not survive if returned. Any great enlargement of the mesh does not appear advisable, since it would afford an opportunity of escape to the mature sole, of which that active species would be extremely likely to avail itself. The remedy seems to lie rather in an alteration of the arrangement of the meshes in the codends, so as to prevent them from closing. On this subject I have been making investigations, but they are not yet sufficiently complete to yield reliable deductions. It is sufficiently evident, as has often been pointed out, that the great breadth of some of

${ }^{1}$ Except fish with air-bladders, caught at considerable depths.

NO. 1207 , VOL. 47$\rceil$ the flat-fish render it impossible to deal with the whole question by restrictions of mesh alone.

The last matter with which I have to deal is the destruction of very small fish by shove-net and shrimp "seines." If it were only possible to induce the men to cull out the small fish in the water they would do no harm at all, and practically I suppose that, as matters are, they do not greatly injure any species of known value except the plaice, although the small number of sole, turbot, and brill destroyed may represent, from the relative scarcity of these species, a more considerable injury than one would suppose. When fishing by day the shove-net men usually return the fish to the sea, but by night this is im. possible, and the seine men do not seem to make any effort in that direction either by day or night.

It is a difficult question to deal with, since the shrimp appears to be almost a necessity to some people; at the same time the small plaice which are destroyed must represent an infinitely greater value than the shrimps. If hatcheries were established, and young turbot, brill, sole, and plaice were enlarged after they had been reared through the delicate larval and metamorphosing stages, it is reasonable to suppose that they would be conveyed or would find their way to the sandy margins, which seem best adapted to the succeeding stages of their life-history, only to fall into the net of the shrimper.

I should say that to prohibit the use of any sort of shore shrimp nets during night-time would be a beneficial measure, but there is perhaps sufficient reason for abolishing the industry altogether. Those engaged in it might be sufficiently compensated at a moderate expenditure, if indeed it be not cuntrary to public policy to admit the existence of a vested interest in an occupation which is essentially injurious to industries affecting a much greater section of the community.

\section{THE NEW TELEPHOTOGRAPHIC LENS.}

IN a small pamphlet of thirty pages, written and published by

Mr. T. K. Dallmeyer, the author brings together the various notices bearing on the subject of his new telephotographic lens that have appeared during the last twelve months. $\mathrm{He}$ also gives an account of the "simple" and "compound" telephotographic lens, with general instructions for their use, including tables of their properties, and a table showing the diameters of circles of illumination necessary to cover the various sized plates used at the present day.

The telephotographic lens is, we may say, the latest advance made in the science of optics as applied to photography. By it we are now able to obtain large pictures of animate things situated at long distances with short exposure. In this invention Mr. Dallmeyer has produced a useful, and what may prove a valuable, instrument, and he has opened up quite a new horizon which will not suffer from lack of workers.

Hitherto the principle involved in the apparatus for the production of large images consisted first in oblaining the primary image, and second, in subjecting this image to the process of enlargement. To obtain the former a concave mirror, or more generally double convex lens, has been employed, while the subsequent magnification has been produced by placing a secondary magnifier or second positive lens behind the plane of the primary image.

This method, except in the case of astronomical work, has not been, we may say, popularly used, for the cumbrousness of the apparatus required, and the length of time necessary for exposure have quite prohibited its use for anything but inanimate subjects.

It is well known that the focal length of a lens is measured for practical purposes from the principal plane passing through one of the nodal points nearest the principal focal plane to that plane: in most lens-constructions this nodal point lies within the lensmount. Now it will be seen that if this nodal point could be thrown in front of the lens, that is, on that side away from the focus, the focal length, if measured from the lens, would be shorter. This is exactly what Mr. Dallmeyer has done. In the simple telephotographic lens the anterior element, which is of large aperture and short focus, is a positive lens, while the posterior is negative, and of a fractional part of the focal length of the former lens. A diagram showing the lenses in position and the path of a ray of light remind one at first sight of the principle of the Galilean telescope, with this difference, that the rays emerging are not divergent, but convergent. In the construction 
under consideration the size of the image thrown on the screen can be varied at will by simply altering the distance between the elements, but the further the lens is from the focussing screen, the more will be the time of exposure.

With such a lens as this Mr. Dallmeyer has taken many excellent pictures, but perhaps the best idea of its properties will be gathered from the facts obtained by photographing - by means of two cameras, one supplied with a "long focus landscape lens," and the other with the "new telephotographic lens"the flame of an oil lamp placed at a distance of 20 feet. With equal extensions of the camera the image of the flame given by the new lens was five times greater than that by the other.

In the compound lens the anterior element before referred to is here replaced by a complete portrait lens, while a negative symmetrical combination takes the place of the posterior element. This lens may be said to be more perfect than the simple lens, Mr. Dallmeyer having been able to introduce considerable improvement in the construction.

Some excellent work done with this lens has been exhibited by Messrs. F. Mackenzie and Annan at the Camera Club. The pictures represented a building at a distance of 500 yards. The first, taken with an ordinary rapid rectilinear lens with an extension of 14 inches, gave the house as $\frac{3}{4}$ of an inch long. The second-with the compound tele-photo lens, extension 9 inches from the back lens-gave $2 \frac{1}{2}$ inches as the size of the house, while the third, with 30 inches' extension, gave the house as $6 \frac{1}{3}$ inches. Although these numbers can give one a very good idea of what this new lens can accomplish, yet the direct copies from photographs inserted in the pamphlet under consideration convey a more vivid impression.

There is no doubt that this lens will find some very valuable applications, that of astronomical photography not being the least of them, for every one knows the great advantage a short telescope has over a long one if the degree of magnification in both are equal.

W.

\section{ARBORESCENT FROST PATTERNS.}

$W^{E}$ have received the following letters with regard to arborescent frost patterns, to which Prof. Meldola called attention in last week's NATURE:-

I AM very glad that Prof. Meldola has called attention to the curved figures of frozen mud (of which the specimens on December 4 were unusually fine), because I hope that some one will explain why the sexangular crystallization which is universal in snow, and general in water, is exchanged both on windows and on muddy pavements for curves. Probably I ought to know all about it, but I cannot remember seeing an explanation, and shall be obliged by reference to one, which will probably be of interest to others besides

62, Camden-square, London, N.W.

G. J. Symons.

THE interesting "fronds" of muddy ice observed by Prof. Meldola (p. I26) are not very uncommon on the pavements in these "Northern Heights." I saw them on the date which he named, and have more than once studied them. I then noticed that the "interstitial" pavement seemed partly cleared of mud, as if the water had drawn this towards the groups of crystals. The mode of formation recalled to my mind certain phenomena in crystal building within rocks, and I suspect the mud has its influence. Indeed, it seems to me very probable that all these "dendritic" growths of crystals are the results of "impeded" or "constrained "crystallization, to some of which I have called attention in noticing a structure in the Charnwood syenite (Quart. Four. Geol. Soc., I89I, p. IOI). On this point Prof. Sullas makes some important remarks in his well-known paper on the Wicklow granites.

T. G. BONNEY.

THE beautiful curved forms assumed by the ice on the paving flags last Sunday were very noticeable in this neighbourhood and IIampstead as well as in other parts of London. What 1 observed were not quite like those described and figured by Prof. Meldola, but resembled rather the scrolls and volutes which are frequently used in decorative art. The finest piece that I saw was in this square, where several of these scrolls radiated from a central point, and spread over several feet of the pavement. A friend, Mr. E. Swain, observed that where one of these scrolls came upon a puddle of clear water the crystals were continued in a straight line. Such forms are not at all unusual in the freezing of muddy water, and at the pre sent moment the puddles in the road opposite my house are

NO. I 2OT, VOL. 47] filled with rectilinear crystals of ice, which assume a curved form in the mud at their margins. The peculiarity on Sunday was their large size and beauty. Something analogous takes place when gold or silver is reduced frem solutions of its salts by more electro-positive metals. Under certain circumstances

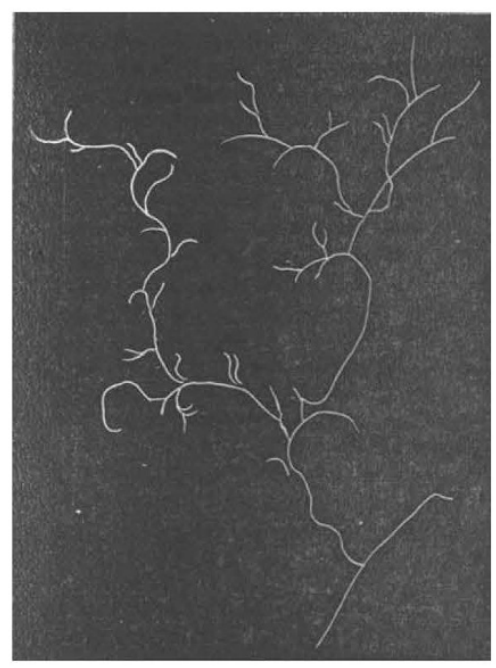

the metal will present itself in the form of curved crystals, if the term be allowable. A pretty spray of gold of this character is figured in the report of my lecture "On the crystallization of silver, gold and other metals," in the proceedings of the Royal Institution, vi., 428. If a piece of cuprous oxide be immersed in a solution of nitrate of silver, there shoot from its surface thin threads of silver, which, after proceeding straight forward for a while, suddenly turn at an angle of $120^{\circ}$ or $60^{\circ}$, and make perhaps many other deviations : but sometimes these threads, instead of being straight, are curved; and in that case the threads that branch from them are curved likewise. A magnified drawing of such a formation is given herewith. These strange departures from the usual rectilinear course of crystal formation are very curious, and deserve more study than has hitherto been given them.

17, Pembridge-square, December Io.

Prof. Meldola's letter (p. I25) has been interesting to me, as I noted a striking and similar phenomenon here on Thursday, December 8 , in the forenoon. The trottoirs of several streets (east, west, north and south) were covered all over with beautiful patterns, somewhat different from Prof. Meldola's illustration, there baing innumerable dark, broad, sharply-contoured leaf-like patches, distant several inches from each other, and connected by finely curved and branched tendril-like stalks. Foggy, with a faint north breeze. I should presume the "leaves" were due to sp.rse drops of sleet fallen during the night. Freiburg, Badenia, December ro. D. WetTekinaN.

THE graceful arborescent frost patterns described by Prof. Meldola in last week's NATURE were very conspicuous on the foot-bridge by the side of Charing Cross railway bridge, on the same morning, this being a situation still more exposed to the wind which he mentions as the probable cause.

December I 2 .

J. T. RICHARDS.

I OBSERVED the same phenomenon as Prof. Meldola describes in NATURE of December 8, on the same date, December 4 , on pavements in Cheltenham, about $10.45 \mathrm{a.m}$. ; after mid-day they had gone. I saw the patterns on pavements running north and south, as well as east and west. They were most exquisite ; some like the illustration, others much more minute; but al ways in a connected design over the whole flag. They had all the appearance of fossil vegetation. I never saw anything of the kind before.

December 13 .

J. J. Armitage,

Mr. A, W. Bennetr and Mr. E. L. Garbett have also sent communications corroborating the phenomenon observed by Prof. Meldola. The former aitributes it to "defoliation of the stones as the result of weathering or wear." 